\section{Not-So-Random Errors: Randomized Controlled Trials Are Not the Only Evidence of the Value of PET-Rebuttal}

TO THE EDITOR: Scheibler et al. imply in the concluding comment of their reply (1) to our letter to the editor (2) that our critique of their paper (3) was neither objective nor "evidence-based." We will leave it to the broader readership to decide the merits of the published arguments and counterarguments. However, we ourselves remain unconvinced that they address our fundamental criticism that such evaluations serve to inappropriately undervalue the strong existing evidence base for the use of PET/CT in oncology. We believe that we have made the case that by placing unreasonable importance on a single dimension of the evidence, that is, trial design, Scheibler et al. potentially misguide policymakers and individuals about appropriate use of this technology. In our view, this is a disservice to our patients that must be strenuously resisted and hence the tone of our prior letter.

As doctors, we observe on a daily basis that PET provides unique information on individual patients that directly results in the avoidance of futile or inappropriate treatments. As clinical researchers, we have contributed significantly to the evidence base that has demonstrated not only the accuracy but also the high impact that PET or PET/CT has on patient care and prognostic stratification. Should we, and clinicians with similar hands-on experience of PET, accept the fundamental premise of Scheibler et al. that this information is untrustworthy or irrelevant in the absence of confirmatory randomized-controlled trial data? Should scientific journals, such as The Journal of Nuclear Medicine, refrain from publishing papers that seek to inform clinical decision making unless randomized-controlled trial methodology has been implemented? We believe the answer to these fundamental questions must be an emphatic no. Most importantly, we reject their statement that "diagnostic accuracy is only a surrogate for patient-relevant outcomes." Rather, we would contend that in cancer management, the accuracy of the tests that guide the application of expensive, toxic, and potentially lethal therapies is of critical relevance to patients as well as to their caregivers and the community.

\section{REFERENCES}

1. Scheibler F, Zumbé P, Janssen I, et al. Not-so-random errors: randomized controlled trials are not the only evidence of the value of PET [reply]. $J$ Nucl Med. 2013;53:1822-1824.

2. Hicks RJ, Ware RE, Hofman MS. Not-so-random errors: randomized controlled trials are not the only evidence of the value of PET [letter]. J Nucl Med. 2012;53: $1820-1822$

3. Scheibler F, Zumbé P, Janssen I, et al. Randomized controlled trials on PET: a systematic review of topics, design, and quality. J Nucl Med. 2012;53:10161025.

Rodney J. Hicks*

Michael S. Hofman

Robert E. Ware

*Peter MacCallum Cancer Institute

12 Cathedral Pl.

East Melbourne, Victoria, Australia 3002

E-mail:rod.hicks@petermac.org

Published online Jan. 18, 2013

DOI: 10.2967/jnumed.112.116020 